\title{
Investigating the role of cortisol and growth hormone in fatty liver development: fatty liver index in patients with pituitary adenomas
}

\author{
Matthias K. Auer ${ }^{1}$ Günter K. Stalla ${ }^{1}$ Mareike R. Stieg ${ }^{1}$
}

Published online: 18 May 2016

(C) The Author(s) 2016. This article is published with open access at Springerlink.com

\begin{abstract}
Purpose Non-alcoholic fatty liver disease (NAFLD) is a hallmark of the metabolic syndrome and has been shown to be an independent predictor of cardiovascular mortality. Although glucocorticoids and growth hormone are known to be implicated in its pathophysiology, it has only rarely been investigated in the context of patients with pituitary insufficiency or former cortisol excess.

Methods Case-control study in patients with biochemically controlled Cushing's disease $(\mathrm{CD} ; \mathrm{N}=33)$ and nonfunctioning pituitary adenomas (NFPA; $\mathrm{N}=79$ ). NAFLD was estimated by calculating the fatty liver index (FLI) including BMI, waist circumference, GGT and triglyceride levels.

Results Although there was no difference in FLI between patients with NFPA and CD, we identified average daily hydrocortisone (HC) intake in those with adrenal insufficiency to be an independent predictor of FLI ( $\beta=1.124$; $p=0.017$ ), even after adjusting for BMI and waist circumference. In line, those with a FLI $>60$ were also taking in average significantly more $\mathrm{HC}$ per day than those with a score $<60(21.05 \mathrm{mg} \pm 5.9$ vs. $17.9 \mathrm{mg} \pm 4.4$; $p=0.01)$. FLI was also the best independent predictor for HbAlc and fasting glucose levels (both $p=0.001$ ). Growth hormone deficiency and replacement therapy were not associated with FLI in either group.

Conclusions While HC dosage affects FLI as an estimate of NFLD in patients with CD and NFPA, the benefit of GH replacement still needs to be determined. In contrast to
\end{abstract}

Matthias K. Auer

mauer@psych.mpg.de

1 RG Neuroendocrinology, Max Planck Institute of Psychiatry, Kraepelinstrasse 2-10, 80804 Munich, Germany reports in CD patients with active disease, NAFLD in those with biochemical control was not different from NFPA patients.

Keywords Adrenal insufficiency · Cushing's disease . Growth hormone $\cdot$ Fatty liver $\cdot$ Cortisol

\section{Introduction}

Non-alcoholic fatty liver disease (NAFLD) is the most common liver disease in western populations and it is closely linked to the development of the metabolic syndrome [1]. The term encompasses simple steatosis of the liver as well as non-alcoholic steatohepatitis (NASH). NASH in turn can ultimately result in liver fibrosis and cirrhosis and increases also the risk for hepatocellular carcinoma [2]. Beyond its contribution to metabolic disturbances, it is also an independent predictor of cardiovascular mortality [3].

Patients with pituitary adenomas in general and those with Cushing's disease (CD) in particular have an increased cardiovascular risk. In case of $\mathrm{CD}$ this is even true for those who have achieved biochemical control [4]. But also patients with non-functioning pituitary adenomas (NFPA), in particular those with impairment of pituitary function, have an increased risk to die from cardiovascular diseases [5]. In particular growth hormone deficiency and adrenal insufficiency may explain for the increase standard mortality ratio in these patients [6]. Pituitary insufficiencies are also common in CD patients [7], therefore potentially contributing in addition to the detrimental effects of longlasting glucocorticoid (CG) excess to metabolic disturbances and cardiovascular mortality [8,9]. The role of pituitary insufficiency on cardiovascular parameters in 
Cushing's disease is only poorly understood and provided controversial results so far [8-11].

NAFLD has only rarely been investigated in the context of pituitary adenomas [12-14], though it represents and interesting candidate to explain for metabolic disturbances and cardiovascular mortality. It is of special interest in this particular patient population as the involvement of GC as well as growth hormone $(\mathrm{GH})$ is suggested to play a fundamental role in the development of NAFLD [15, 16].

In line, in a study with CD patients with active disease, the estimated prevalence of NAFLD by CT measurements was $20 \%$ and closely related to visceral adiposity [12]. Vice versa, in the general population, increased exposure to GCs is associated with NAFLD [16]. These findings underline the critical role of hepatic exposure to GCs for the development of NAFLD.

The role of the GH/insulin-like growth factor-1(IGF-1) system in this context is less clear. Both GH and IGF-1 are however believed to be important in the regulation of hepatic lipid metabolism [17]. Growth hormone deficiency (GHD) appears to be associated with increased hepatic lipid content [14], however interventional studies have yielded controversial results [13, 14].

Although currently the diagnosis of NAFLD requires a liver biopsy, non-invasive procedures have been developed in the past that show adequate concordance with histological results. This includes the fatty-liver-index (FLI) [18] which has been demonstrated to be a useful tool to predict the presence of NAFLD as it shows high accordance with imaging [19] as well as histological criteria for NAFLD [20]. The index has been shown to be a useful predictor of arteriosclerosis development and all-cause mortality, independent of established classical risk factors in particular in those patients with a score $\geq 60$ [21].

In the present study we therefore investigated the effects of long-lasting former cortisol excess in CD on FLI as a marker of NAFLD in comparison to patients with NFPA, to disentangle the different effects of past cortisol excess, present adrenal insufficiency and GHD on NAFLD. We also investigated if FLI would be a good predictor in this special population for disturbances in glucose metabolism and further classical cardiometabolic risk factors.

\section{Methods}

Suitable patients were selected from a patient cohort of the department of Clinical Neuroendocrinology of the Max Planck Institute of Psychiatry in Munich, Germany who had been included in the Network of Excellence for Neuroendocrine Tumors Munich (NeoExNET), a registry and biobank alliance of several regional academic institutions. Data necessary for the calculation of the FLI had not been systematically assessed before 2012 , so only patients that had visited our department between the years 2012-2014 were included in the present analysis. We only included patients with $\mathrm{CD}$ who were biochemically cured for at least 12 month prior to the analysis $(\mathrm{N}=33)$. Five $\mathrm{CD}$ patients were receiving $\mathrm{CD}$-specific medications at the time of study inclusion (one cabergolin, three azol-derivates and one pasireotide).

We further included patients with NFPA $(\mathrm{N}=79)$. Patients were excluded if GHD had not been documented by appropriate stimulation tests [22]. We also only included patients who had been diagnosed with GHD for at least 1 year prior to the investigation. To compare for the sustained effects of GH-substitution, we also only included those in the GH-treated group who had at least been treated with $\mathrm{GH}$ for 12 months prior to the study inclusion.

Adrenal insufficiency had to be documented by adequate stimulation tests [23]. Evaluation of further pituitary function, respectively adequateness of treatment based on basal measurements of thyroid-stimulating hormone (TSH), free thyroxine, free triiodothyronine, luteinizing hormone $(\mathrm{LH})$, follicle-stimulating hormone (FSH), and total testosterone (in men) or oestradiol (in women). Further parameters were assessed after an overnight fast between 8 and 11:30 a.m. using routine clinical methods at the local laboratory. IGF-1 and GH were measured on the IMMULITE $200{ }^{\circledR}$ analyzer (Siemens, Los Angeles, CA).

In women in the fertile age range, secondary hypogonadism was defined as low LH/FSH in women with secondary amenorrhea for at least 1 year. In postmenopausal women, secondary hypogonadism was documented when gonadotropin levels were inappropriately low for the postmenopausal age. In men, secondary hypogonadism was defined as a low testosterone level with an inappropriate low LH/FSH and secondary hypothyroidism as low free T4 (FT4) with an inappropriately low serum TSH. Patients with adrenal insufficiency were treated with conventional hydrocortisone usually divided into 2-3 doses per day. Secondary hypothyroidism was treated with levothyroxine. LH/FSH deficiency was treated with testosterone in men (gel or intramuscular injections) and with estrogen/progesterone replacement in women or in case of past hysterectomy with estradiol only. Most women were receiving transdermal estradiol preparations.

Patients were also excluded if average alcohol intake was $>30 \mathrm{~g} /$ day for men and $>20 \mathrm{~g}$ for women or if they had known cirrhosis, hepatitis B or C. Height and weight were measured to the nearest $0.5 \mathrm{~cm}$ and $0.1 \mathrm{~kg}$, respectively. Waist circumference was measured to the nearest $0.5 \mathrm{~cm}$. History of medication intake and comorbidities was retrieved from the patient files and by interview. FLI was calculated according to an equation including BMI, waist circumference, GGT and triglyceride levels [18]. All 
patients gave written informed consent and the study was approved by the ethical review board of the Ludwig Maximilian University of Munich.

\section{Statistical analysis}

Statistical analysis was conducted using SPSS 21.0 for Windows software (SPSS Inc). Quantitative data are expressed as mean \pm standard deviation (SD) or standard error (SE), and categorical data are expressed as percentages. Differences between groups were performed using $\chi^{2}$-tests. Normal distribution of variables was tested by Kolmogorov-Smirnov-Test and skewed variables were log-transformed for further testing procedures. Differences between CD and NFPA patients were evaluated with an analysis of covariance (ANCOVA) controlling for age and gender which was different between the groups. Relations between the outcome variables and continuous variables were evaluated by univariate Pearson's correlation coefficients or Spearman as appropriate. Multivariate linear regression models were used to investigate the relationship between depended and independent variables, including potential influential factors. Logistic regression analysis was used to test the independence of dichotomous outcome variables with their significant correlates in univariate models. Statistical tests were two-sided, and significance was set at a value of $p<0.05$.

\section{Results}

\section{General characteristics}

In accordance with the general epidemiological characteristics of these two pituitary adenoma entities, significantly more patients with $\mathrm{CD}$ were women than patients with NFPA and they were also significantly younger (50.3 years \pm 13.4 vs. 61.6 years $\pm 14.5 ; \quad p=0.037$ ). Fewer CD patients had a macroadenoma at the time of diagnosis $(p>0.001)$ but radiotherapy was more frequently applied $(p=0.005)$. Adjusted mean systolic and diastolic blood pressure was not significantly different between NFPA and CD patients and same was true for those who had already been diagnosed and pretreated with antihypertensive drugs. Adjusted weight, BMI, and waist circumference did not differ between the groups. There was also no significant difference in the rate of patients with pre-diagnosed and pre-treated type 2-diabetes, intake of anti-hyperlipidemic drugs and also not for adjusted fasting glucose, HbA1c, total cholesterol, HDL, LDL, ALAT, ASAT, AP, GGT fasting triglyceride levels or IGF-1.

There was no significant difference in the total rate of pituitary insufficiency or total number of affected pituitary axes, but secondary hypogonadism $(p=0.007)$ and GHD $(p=0.015)$ was more common in NFPA patients than in those with $\mathrm{CD}$. There was only a trend for more secondary adrenal insufficiencies in NFPA patients $(p=0.072)$ and as five patients had been bilaterally adrenalectomized in the course of $\mathrm{CD}$, there was no significant difference with regard to the total rate of adrenal insufficiencies between the both groups. Average daily HC intake did not significantly differ between the groups. There was also no significant difference in overall untreated hypogonadism [defined as primary (=menopause) + secondary] and untreated GHD. FLI in NFPA patients in comparison to CD patients did not differ and same was true for the proportion of patient with an FLI above or below 60 (Table 1).

\section{FLI as a measure of NAFLD}

In the entire study population FLI correlated with female sex $\quad(\mathrm{r}=-0.313 ; \quad p=0.001), \quad$ Hb1Ac $\quad(\mathrm{r}=0.328$; $p=0.001)$, fasting glucose $(\mathrm{r}=0.404 ; p<0.001)$, HDL $(\mathrm{r}=-0.425 ; p<0.001)$, BMI $(\mathrm{r}=0.852 ; p<0.001)$, GGT $(\mathrm{r}=0.499 ; p>0.001)$, triglycerides $(\mathrm{r}=0.456$; $p<0.001)$, systolic $(\mathrm{r}=0.332 ; p<0.001)$ and diastolic BP $(\mathrm{r}=0.415 ; p<0.001)$, ASAT $(\mathrm{r}=0.432 ; p>0.001)$ and ALAT $(\mathrm{r}=0.357 ; p<0.001)$ but not with the ASAT/ ALAT-ratio. There was no significant difference in FLI scores between patients with and without overt hypogonadism. Same was true for those with untreated GHD in comparison to those without GHD or those that were on adequate replacement therapy. There was also no significant correlation with IGF-1 levels $(p=0.869)$ in univariate analysis. FLI did not differ between patients with and without adrenal insufficiency but there was a trend for a positive correlation of average daily hydrocortisone intake $(\mathrm{r}=0.253, p=0.086)$.

To assess independent predictors of FLI, a multivariate regression model using backward stepwise removal was used, entering FLI as a dependent variable and age, sex, diagnosis (CD vs. NFPA), untreated hypogonadism (primary + secondary), adrenal insufficiency, average daily intake of hydrocortisone replacement, untreated GHD, IGF-1 and hypothyroidism.

In this model, the only independent predictors were sex ( $\beta=-22.535 ; p=0.016)$ and average daily hydrocortisone intake ( $\beta=1.804, p=0.042)$. Even when BMI and waist circumference, which are part of the FLI calculation, were included in the model, average daily hydrocortisone intake remained an independent predictor of FLI scores $(\beta=1.124 ; p=0.017$; Table 2$)$.

In line, those with a FLI $>60$ were also taking in average a significantly higher daily HC-dosage than those with a score $<60(21.05 \mathrm{mg} \pm 5.9$ vs. $17.9 \mathrm{mg} \pm 4.4$; $p=0.01$; Fig. 1). This finding was independent of age, sex 
Table 1 General characteristics

\begin{tabular}{lccccccc}
\hline & \multicolumn{2}{l}{ Cushing's disease } & & \multicolumn{2}{l}{ NFPA } & \multirow{2}{*}{$p$} \\
\cline { 2 - 3 } & $\mathrm{N}$ & $\%$ & & $\mathrm{~N}$ & $\%$ & \\
\hline General characteristics & & & & & & \\
Male & 1 & 3 & & 43 & 54.4 & $<\mathbf{0 . 0 0 1}$ \\
Female & 32 & 97 & & 36 & 45.6 & \\
\hline Age (years) & 50.3 & 13.4 & & 61.6 & 14.5 & $\mathbf{0 . 0 4}$ \\
\hline & Mean & $\mathrm{SD}$ & & Mean & $\mathrm{SD}$ & $p$ \\
\hline
\end{tabular}

Tumorsize

$\begin{array}{lrlrrr}\text { Macroadenoma } & 9 & 27.3 & 78 & 98.7 & <\mathbf{0 . 0 0 1} \\ \text { Microadenoma } & 23 & 69.7 & 1 & 1.3 & \\ \text { NA } & 1 & 3.0 & 0 & 0.0 & \end{array}$

Treatment

\begin{tabular}{lllllll}
$\begin{array}{l}\text { Surgery } \\
\text { Radiotherapy }\end{array}$ & 33 & 100 & 72 & 91.1 & & 0.712 \\
& 13 & 39.4 & 12 & 15.2 & & $\mathbf{0 . 0 0 5}$ \\
& & Mean & SE & Mean & SE & $p$ \\
\hline $\begin{array}{l}\text { Anthropometry } \\
\text { Weight }(\mathrm{kg})\end{array}$ & 75 & 3.3 & 78 & 2.8 & 0.535 \\
$\begin{array}{l}\text { BMI }\left(\mathrm{kg} / \mathrm{m}^{2}\right) \\
\text { Waist }(\mathrm{cm})\end{array}$ & 26.6 & 1 & 27.8 & 0.6 & 0.317 \\
$\begin{array}{l}\text { Systolic blood pressure (mmHg) } \\
\text { Diastolic blood pressure }\end{array}$ & 128.8 & 3.1 & 136.9 & 1.8 & 0.370 \\
$(\mathrm{mmHg})$ & 85.2 & 1.9 & 85.2 & 1.1 & 0.994 \\
\hline \multicolumn{1}{c}{$\mathrm{N}$} & $\%$ & $\mathrm{~N}$ & & $\%$ & & $p$ \\
\hline
\end{tabular}

Drug intake

Anti-hypertensive treatment

$\begin{array}{llllll}\text { No } & 19 & 57.6 & 19 & 57.6 & 0.094 \\ \text { Yes } & 14 & 42.4 & 14 & 42.4 & \end{array}$

Anti-hyperglycemic treatment

$\begin{array}{lrrrrr}\text { No } & 29 & 87.9 & 68 & 86.1 & 0.798 \\ \text { Yes } & 4 & 12.1 & 11 & 13.9 & \end{array}$

Dyslipidemia treatment

\begin{tabular}{lrlrlll} 
No & 28 & 84.8 & 59 & 74.7 & 0.239 \\
Yes & 5 & 15.2 & 20 & 25.3 & \\
\hline & Mean & SE & Mean & SE & $p$ \\
\hline
\end{tabular}

\section{Laboratory}

Fasting glucose (mg/dl)

Hbalc (\%)

Total cholesterol (mg/dl)

$\begin{array}{lllll}87.3 & 2.8 & 84.1 & 1.7 & 0.367\end{array}$

HDL (mg/dl)

LDL (mg/dl)

Triglycerides $(\mathrm{mg} / \mathrm{dl})$

Gamma-GT (U/l)

$\operatorname{ALAT}(\mathrm{U} / \mathrm{l})$

ASAT (U/l)

$\begin{array}{lllll}5.5 & 0.1 & 5.3 & 0 & 0.113\end{array}$

$\begin{array}{lllll}212.3 & 8.2 & 216.4 & 5 & 0.690\end{array}$

$\begin{array}{lllll}63.6 & 3.8 & 59.5 & 2.2 & 0.389\end{array}$

$\begin{array}{lllll}136.7 & 7.2 & 140.1 & 4.3 & 0.708\end{array}$

$\begin{array}{lllll}145.3 & 15.9 & 141.9 & 10.1 & 0.866\end{array}$

$\begin{array}{lllll}32.8 & 5.7 & 32.8 & 5.7 & 0.801\end{array}$

$\begin{array}{lllll}23.0 & 2.5 & 26.2 & 1.5 & 0.303\end{array}$

$\begin{array}{lllll}22.4 & 1.7 & 26.6 & 1 & 0.450\end{array}$

Table 1 continued

\begin{tabular}{|c|c|c|c|c|c|c|}
\hline & & Mean & SE & Mean & SE & $p$ \\
\hline \multirow[t]{2}{*}{$\mathrm{AP}(\mathrm{U} / \mathrm{l})$} & & 64.5 & 4.2 & 69.3 & 2.6 & 0.359 \\
\hline & $\mathrm{N}$ & $\%$ & $\mathrm{~N}$ & & $\%$ & $p$ \\
\hline \multicolumn{7}{|l|}{ FLI } \\
\hline \multirow[t]{2}{*}{ Mean FLI } & 47.6 & 6 & 49.1 & & 3.6 & 0.846 \\
\hline & Mean & SE & Mean & & SE & $p$ \\
\hline FLI $<60$ & 23 & 69.7 & 26 & & 32.9 & 0.208 \\
\hline FLI $>60$ & 10 & 30.3 & 16 & & 20.3 & \\
\hline IGF1 (ng/dl) & 118.7 & 14.3 & 141 & & 7.8 & 0.201 \\
\hline \multicolumn{7}{|c|}{ Pituitary function } \\
\hline \multicolumn{7}{|c|}{ Pituitary insufficiency } \\
\hline No & 10 & 30.3 & 18 & & 22.8 & 0.402 \\
\hline Yes & 23 & 69.7 & 61 & & 77.2 & \\
\hline
\end{tabular}

Number of pituitary deficiencies

$\begin{array}{rrrrl}0 & 8 & 24.2 & 15 & 19 \\ 1 & 9 & 27.3 & 11 & 13.9 \\ 2 & 5 & 15.2 & 8 & 10.1 \\ 3 & 7 & 21.2 & 18 & 22.8 \\ 4 & 3 & 12.1 & 27 & 34.2\end{array}$

0.07

Secondary hypogonadism

\begin{tabular}{cccccc} 
No & 20 & 60.6 & 26 & 32.9 & $\mathbf{0 . 0 1}$ \\
Yes & 13 & 39.4 & 53 & 67.1 & \\
Menopause & 6 & 18.2 & 9 & 11.4 & 0.724 \\
\multicolumn{2}{l}{$\begin{array}{l}\text { Total sex steroid deficiency } \\
\text { No }\end{array}$} & & & & \\
Yes & 25 & 75.8 & 52 & 65.8 & 0.301 \\
Y & 8 & 24.2 & 26 & 32.9 &
\end{tabular}

Secondary adrenal insufficiency

$\begin{array}{llllll}\text { No } & 24 & 72.7 & 43 & 54.4 & \mathbf{0 . 0 7}\end{array}$

Total adrenal insufficiency*

$\begin{array}{llllll}\text { No } & 19 & 57.6 & 43 & 54.4 & 0.072\end{array}$

$\begin{array}{lllll}\text { Yes } & 14 & 42.4 & 36 & 45.6\end{array}$

\begin{tabular}{llllll}
\hline & Mean & SE & Mean & SE & $p$ \\
\hline $\begin{array}{c}\text { Average daily hydrocortisone } \\
\text { intake (mg; range } 10-30 \mathrm{mg})\end{array}$ & 20.4 & 3.3 & 18.7 & 5.7 & 0.324 \\
\hline
\end{tabular}

\begin{tabular}{llllll}
\hline $\mathrm{N}$ & $\%$ & $\mathrm{~N}$ & $\%$ & $p$ \\
\hline
\end{tabular}

Secondary hypothyroidism

\begin{tabular}{lrrrrr} 
No & 15 & 45.5 & 47 & 59.5 & 0.173 \\
Yes & 18 & 54.5 & 32 & 40.5 & \\
GHD & & & & & \\
No & 19 & 57.6 & 26 & 32.9 & $\mathbf{0 . 0 2}$ \\
Yes & 14 & 42.4 & 53 & 67.1 & \\
Treated & 7 & 21.2 & 29 & 36.7 & 0.109 \\
Untreated & 7 & 21.2 & 24 & 30.4 & \\
\hline
\end{tabular}


Table 1 continued

\begin{tabular}{lrrrrr}
\hline & $\mathrm{N}$ & $\%$ & $\mathrm{~N}$ & $\%$ & $p$ \\
\hline Overt GHD & & & & & \\
No & 26 & 78.8 & 55 & 69.6 & 0.323 \\
Yes & 7 & 21.2 & 29 & 36.7 & \\
Diabetes insipidus & & & & & \\
No & 31 & 93.9 & 69 & 87.3 & 0.303 \\
Yes & 2 & 6.1 & 10 & 12.7 & \\
\hline
\end{tabular}

$p$-value (bold if significant)

$G H D$ Growth hormone deficiency, FLI fatty liver index, $S E$ standard error, $S D$ standard deviation, $N A$ not available

* Including five patients primary adrenal insufficiency due to adrenalectomy

and pituitary function (Table 3), but did however not survive if BMI and waist circumference were included in the model (data not shown).

\section{Predictors for cardiovascular risk factors}

We determined which factors might predict differences in other cardio-metabolic variables such as total cholesterol levels, HDL, LDL, systolic and diastolic BP, fasting glucose and $\mathrm{HbA1c}$ levels in a stepwise linear regression analysis (Table 4). We performed the analysis once for the whole study population and once only for those who were not already receiving medical treatment for arterial hypertension, dyslipidemia or type 2 diabetes, respectively.

Every regression model included age, sex, diagnosis (CD vs. NFPA), untreated hypogonadism (primary + secondary), average dosage of hydrocortisone replacement, untreated GH deficiency, IGF-1 and FLI scores as independent variables.

FLI ( $p=0.032)$ was the best single predictor for HDLcholesterol levels. If those were excluded from the analysis that had already received anti-hyperlipidemic treatment,

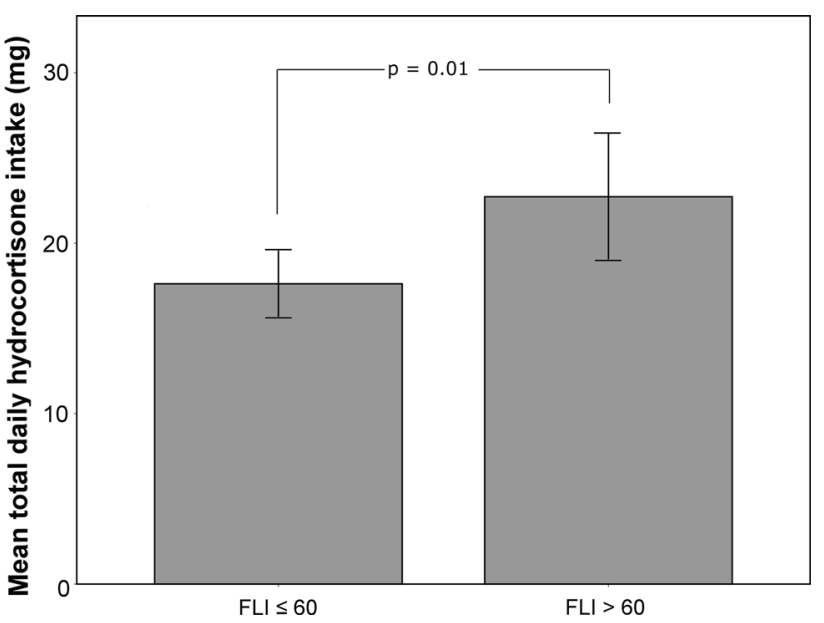

Fig. 1 Average daily hydrocortisone intake and FLI $>60$

only FLI ( $p=0.013)$ and GHD remained significant $(p=0.037)$. Age was the only independent predictor for systolic BP $(p<0.001)$, while age $(p=0.001)$ and sex ( $p=0.012$ ) were predictive for systolic BP in those who did not already receive antihypertensive medication. Female sex was the only independent negative predictor of diastolic BP and remained significant after excluding those with anti-hypertensive treatment $(p=0.001)$. HbA1c was independently predicted by FLI $(p=0.001)$, age $(p=0.006)$ and male sex $(p=0.031)$. FLI remained the only significant predictor if those with anti-hyperglycemic treatment were excluded from the analysis $(p=0.001)$. FLI was also the only independent predictor for fasting glucose levels for those with $(p=0.001)$ and without antidiabetic treatment ( $p=0.002$; Table 4$)$.

If FLI was substituted by the separate variables used for its equitation (BMI, waist circumference, triglycerides and GGT), GGT was the best determinant for HbA1c levels in the whole study cohort $(p=0.016)$ and after excluding

Table 2 Predictors of the fatty liver index

\begin{tabular}{lrrrrr}
\hline Model & $\beta$ & SE & $p$ value & \multicolumn{2}{l}{ Confidence interval (CI; 95.0 \%) } \\
\cline { 5 - 6 } & & & Lowest & Highest \\
\hline Model 1* & & & & -39.298 & -2.006 \\
Female sex & -22.535 & 8.971 & 0.016 & 0.072 & 3.536 \\
HC dosage & 1.804 & 0.859 & 0.042 & & 2.036 \\
Model 2** & & & & 0.212 & 5.151 \\
HC dosage & 1.124 & 0.451 & 0.017 & 3.023 & 0.563 \\
BMI & 4.087 & 0.526 & $<0.001$ & 0.028 & \\
Waist & 0.296 & 0.132 & 0.031 & & \\
\hline
\end{tabular}

$\beta$, Partial regression coefficient; $H C$, hydrocortisone; $S E$, standard error of partial regression coefficient * Included age, sex, diagnosis, untreated GHD, adrenal insufficiency, untreated hypogonadism, secondary hypothyroidism

** + BMI + Waist circumference 
Table 3 Predictors for an FLI $>60$

\begin{tabular}{llllll}
\hline \multicolumn{6}{l}{ Model with FLI (used as a dichotomic variable; FLI $\geq 60$ and FLI $<60)^{*}$} \\
\hline Model & $\beta$ & SE & $p$ value & Confidence interval (CI; 95.0 \%) \\
\hline Sex (male) & 2.758 & 0.845 & 0.027 & 0.013 & 00.768 \\
HC dosage & 0.201 & 0.082 & 0.02 & 1.041 & 10.587 \\
\hline
\end{tabular}

$\beta$, Partial regression coefficient; $S E$, standard error of partial regression coefficient; $H C$, hydrocortisone

* Including age, sex, diagnosis, hypogonadism, secondary hypothyroidism, adrenal insufficiency, untreated GHD

Table 4 Predictors of cardiovascular risk factors

\begin{tabular}{|c|c|c|c|c|c|c|c|c|}
\hline \multirow[t]{2}{*}{ Dependent variable* } & \multicolumn{4}{|l|}{ All patients } & \multicolumn{4}{|l|}{ Not pretreated $* *$} \\
\hline & Independent variable & $\beta$ & SE & $p$ value & Independent variable & $\beta$ & SE & $p$ value \\
\hline \multirow[t]{2}{*}{ HDL } & \multirow[t]{2}{*}{ FLI } & \multirow[t]{2}{*}{-0.262} & \multirow[t]{2}{*}{0.118} & \multirow[t]{2}{*}{0.032} & FLI & -0.356 & 0.134 & 0.013 \\
\hline & & & & & GHD & 18.567 & 8.435 & 0.037 \\
\hline \multirow[t]{2}{*}{ Systolic blood pressure (mmHg) } & \multirow[t]{2}{*}{ Age } & \multirow[t]{2}{*}{0.851} & \multirow[t]{2}{*}{0.180} & \multirow[t]{2}{*}{$<0.001$} & Age & 0.426 & 0.152 & 0.001 \\
\hline & & & & & Sex & -13.622 & 4.488 & 0.012 \\
\hline Diastolic blood pressure $(\mathrm{mmHg})$ & Sex & -10.184 & 2.723 & 0.001 & Sex & -7.852 & 2.731 & 0.010 \\
\hline \multirow[t]{3}{*}{ HbAlc $(\%)$} & FLI & 0.008 & 0.002 & 0.001 & FLI & 0.235 & 0.064 & 0.001 \\
\hline & Age & 0.014 & 0.005 & 0.006 & & & & \\
\hline & Sex & 0.348 & 0.156 & 0.031 & & & & \\
\hline Fasting glucose $(\mathrm{mg} / \mathrm{dl})$ & FLI & 0.230 & 0.068 & 0.002 & FLI & 0.235 & 0.064 & 0.001 \\
\hline
\end{tabular}

FLI Fatty liver index

* The predictive variables were age, sex, diagnosis, FLI, hypogonadism, HC dosage and untreated GHD and IGF-1

** Patients excluded taking anti-hyperglycemic drugs (for $\mathrm{HbA1c}$, fasting glucose), antihypertensive medication (for systolic, diastolic BP), antihyperlipidemic drugs (for total cholesterol, HDL, LDL), respectively

those with pretreated diabetes mellitus type $2(p=0.012)$. GGT was also the best predictor for fasting glucose levels $(p<0.001$; Table 5).

\section{Discussion}

In the present study we could show that $\mathrm{HC}$ dosage was an independent predictor of FLI as a marker of NAFLD. This association also remained significant after accounting for waist circumference and BMI. HC intake was also significantly higher in those with an FLI score $>60$ which has been shown to have a high predictive value for NAFLD in histological analysis [24]. This indicates that an increased hepatic exposure with hydrocortisone does not only impact hepatic lipid accumulation via an increase in visceral adiposity, which is a well-established consequence of hypercortisolism [25] and may even persist after achievement of normocortisolism [10], but also by direct effects. The regression analysis indicates that every $\mathrm{mg}$ of $\mathrm{HC}$ results in average in an independent increase of 1.1 units in the FLI. Though this at first glance seems to be only a moderate increase, it has also to be kept in mind that it has been shown in the general population that an increase of the FLI
Table 5 Individual analysis of the components of the fatty liver index

\begin{tabular}{lccc}
\hline & $\beta$ & SE & $p$ value \\
\hline $\begin{array}{l}\text { Model for Hbalc } \\
\text { Model 1* } \\
\text { GGT }\end{array}$ & 0.400 & 0.155 & \\
$\begin{array}{l}\text { Model 2** } \\
\text { GGT }\end{array}$ & 0.342 & 0.124 & 0.016 \\
$\begin{array}{l}\text { Model for fasting } \\
\text { Model 1* } \\
\text { GGT }\end{array}$ & & 0.012 \\
Model 2** & 18.988 & 4.297 & $<0.001$ \\
GGT & 18.833 & 3.237 & $<0.001$ \\
\hline
\end{tabular}

The predictive variables were age, sex, diagnosis, overt hypogonadism, HC dosage and untreated GHD, triglycerides, BMI, GGT, waist circumference

* All patients

** Only patients without anti-diabetic drugs

by only one unit may result in an increased chance of developing NAFLD by $5.8 \%$. It is known that GC treatment may result in liver fat accumulation [26], however, 
this has rather been reported in the context the administration of supraphysiological dosage due to its anti-inflammatory effect in inflammatory diseases [27]. Although there is also evidence for general hypothalamo-pituitaryadrenal (HPA) overactivity in NAFLD patients [28], data supporting a more tissue specific role of GCs in the pathogenesis of NAFLD are even more compelling.

These data show that direct cortisol exposure to liver is a key mediator of liver fat metabolism and NAFLD development [26]. The glucocorticoid receptor (GR) is a critical regulator of liver glucose and lipid homeostasis [29], mediating effects on hepatic lipid metabolism by directly promoting liver fat accumulation via an increase in lipoproteins secretion and up-regulation of enzymes involved in fatty acid synthesis [30] and inhibition in liverspecific fatty acid oxidation [31]. In line, liver-specific knockdown of the GR expression ameliorates steatosis severity [32].

A critical role seems to be played by the local metabolism of glucocorticoids, in particular conversion of cortisone to cortisol by the $11 \beta$-hydroxysteroid dehydrogenase type 1 (11 $\beta$-HSD1)-enzyme that is primarily found in visceral adipose and liver tissue [33]. Hepatic [34] as well as visceral $11 \beta$-HSD1 [35] have both been shown to play a significant role in the etiology of the metabolic syndrome. This enzyme is in particular overexpressed in visceral fat of obese subjects resulting in cortisol-overexposure of the liver by the splanchnic venous system [36]. This is of certain importance as already in metabolically healthy individuals, splanchnic $11 \beta$-HSD1 reactivation of cortisone alone is expected to account for approximately one fourth of circulating cortisol levels [33].

Correspondingly, adipose tissue specific knock-out of $11 \beta$-HSD1 in animal models protects from the development of a metabolic syndrome-like phenotype despite systemic corticosteroid excess [35]. In turn, mice overexpressing $11 \beta-H S D 1$ in the fat tissue show unaltered systemic GC levels while GC levels are increased in portal vein and as a consequence, these mice are developing impaired hepatic lipid clearance and steatosis [34]. On the one hand selective overexpression of $11 \beta-H S D 1$ results in the development of all features of the metabolic syndrome expect obesity [34], on the other hand, selective knock-out of hepatic $11 \beta$-HSD1 is not sufficient to prevent features of the MS and steatosis, when visceral $11 \beta-H S D 1$ is still active and animals are exposed to high doses of GC.

These findings underline the critical role of hepatic exposure to GCs for the development of NAFLD and the metabolic syndrome and have promoted the development of selective inhibitors of 11ß-HSD1 [37-40].

Again, while the effects of liver specific 11ß-HSD1 inhibition on metabolic parameters have been less convincing [39], the use of an 11 $\beta$-HSD1 inhibition that targets both, adipose and liver $11 \beta$-HSD1 has shown beneficial results in type 2 diabetics in addition to metformin therapy in terms of significant improvements in glycemic control and dyslipidemia [40]. The importance of local and in particular visceral glucocorticoid activation is further underscored by the fact that patients who have been treated with these drugs show significant improvement in metabolic parameters despite a compensatory increase in $\mathrm{ACTH}$ and subsequently unaltered systemic cortisol levels. In addition, it was further demonstrated that the improvement in triglyceride levels and hemoglobin Alc was even more promising in those with a higher BMI though there was no difference in baseline metabolic parameters in this regard, potentially due to the higher $11 \beta$-HSD1 expression as a result of increased visceral adipose tissue in these subjects.

All these findings highlight the importance of hepatic GC exposure via the portal venous system and coming back to the findings of our study, it has to be kept in mind that in contrast to individuals without adrenal insufficiency, where cortisol is directly secreted from the adrenals into the systemic circulation, oral intake of $\mathrm{HC}$ as hormone replacement therapy results in a higher liver exposure as it will first enter the portal venous system and therefore result in a relatively increased liver exposure.

In keeping, patients with secondary adrenal insufficiency have an increased overall mortality in particular if they take more than $20 \mathrm{mg}$ per day [41] and also show an unfavorable cardiometabolic risk profile. In contrast, our data do not indicate that preceding hypercortisolism as in cured $\mathrm{CD}$ has a sustained impact on the development of NAFLD, making other factors more likely to contribute to the poor cardiometabolic outcome reported in the literature such as persisting visceral obesity [10].

Adams and colleagues demonstrated in a longitudinal study in a small subset of patients with hypopituitarism that NAFLD development may finally resulting in NASH, fibrosis, cirrhosis and hepatocellular carcinoma, even demanding liver transplantation due to liver failure [42]. However, a large proportion of this small subgroup investigated, was suffering from hypothalamic obesity, potentially differing in terms of NAFLD pathophysiology in comparison to NFPA patients. According to the authors, almost all patients were on $\mathrm{HC}$ replacement therapy, but they do not report on dosage.

In contrast to the role of HC-, GHD, respectively GHD replacement therapy did not seem to have a significant influence on FLI as a marker of NAFLD in our study cohort, neither in CD nor in NFPA patients.

Nishizawa and colleagues [14] reported on a high prevalence of NAFLD of up to $70 \%$ in GHD patients and also a high prevalence of NASH. They also documented a significant improvement in terms of liver histology and liver enzymes in a subgroup of patients receiving GH. The 
high prevalence of NAFLD and NASH may be explained by a high rate of patients with craniopharyngeoma included, potentially suffering from hypothalamic damage. Though controls were matched for BMI, these patients may represent a distinct entity which is not directly comparable with NFPA patients. In this patient cohort, most patients were also suffering from adrenal insufficiency but the authors do not report on replacement regimens. In contrast Garnder et al. [13] who estimated NAFLD by means of magnetic resonance spectroscopy did not find an increased prevalence of NAFLD in comparison to matched controls. In this cohort only a minority of patients was suffering from adrenal insufficiency. We can only speculate on the discrepant findings in these studies but etiology of GHD and extent of accompanying pituitary insufficiencies and subsequent replacement regimens may play a role in this context. It has to be kept in mind that there is a close interaction between the different hormonal axes. GH for example is known to suppress $11 \beta$-HSD1 activity and therefore reducing cortisol exposure.

FLI in our cohort was an independent predictor for conventional cardiovascular risk factors such as $\mathrm{HbA} 1 \mathrm{c}$, fasting glucose and HDL cholesterol. These findings are in accordance with the literature [24]. HbAlc and fasting glucose were best predicted by GGT-levels if analysis of the four factors contributing to its calculation were investigated separately. This finding is of interest as GGT levels have also been suggested to be predictive for mortality also independent of the presence of NAFLD [41].

Apart from the obvious that $\mathrm{HC}$ replacement dosage in patients with adrenal insufficiency should be as high as necessary but as low as possible, the clinical implications of our findings might include to further investigate the effects of different $\mathrm{HC}$-formulations and application routes such as modified-release $\mathrm{HC}$ and $\mathrm{HC}$ via continuous subcutaneous infusion (CSI) on NAFLD development. Modified-release $\mathrm{HC}$ has shown beneficial effects with regard to metabolic outcome [43-45], although it is still not completely clear if this is solely due to a reduced overall bioavailability or due to the more physiological $\mathrm{HC}$ release. It has been shown that patients who had switched from conventional to a dual-release regimen may benefit in terms of cardiometabolic parameters without negative effects on quality of life [43]. Studies comparing conventional $\mathrm{HC}$ to extended-release $\mathrm{HC}$ showed in particular significantly lower levels of triglycerides and BMI [43, 44], both being part of the FLI calculation while others have shown a reduction in waist circumference but not on triglycerides [45].

On the other hand if you follow our argumentation that the direct hepatic $\mathrm{HC}$ exposure via the portal circulation may have more detrimental effects with regard to NAFLD development, the administration of $\mathrm{HC}$ by CSI should result in benefits with regard to liver steatosis. The so far available pilot studies on $\mathrm{HC}$ administration via CSI did not investigate the effects on NAFLD, but showed no benefits with regard to glucose metabolism that is at least pathophysiologically closely related to liver steatosis as also being shown in our study by the FLI and GGT being best predictor for fasting glucose and HbAlc levels. The interpretation of the results of these studies is however hampered by the fact that in one study CSI resulted in a significant increased overall $\mathrm{HC}$ exposure in comparison to the oral dosage potentially counteracting any beneficial effects exerted by the different route of application and in the other study area under the curve (AUC) for cortisol exposure was only determined during the euglycaemichyperinsulinaemic clamp test [46]. It remains therefore speculative if a same-dose exposure to $\mathrm{HC}$ given parenterally would be better for liver and metabolic health than oral application.

There are some limitations that have to be taken into consideration for the interpretation of our results. The major limitation refers to the use of an index for determining NAFLD. Whilst non-invasive assessments of NAFLD as the FLI are able to provide accurate measurements of increased liver fat, it cannot replace staging of disease by liver biopsy as they have lower accuracy in quantifying steatosis. However, the index has been proven highly accurate in detecting a fatty liver [18] and most studies in western populations have shown that a FLI $<30$ has an accuracy for excluding NAFLD between 80 and $87 \%$ while a cut off of $>60$ has a specificity of $80 \%$ for detecting NAFLD, though cut-off points may be different [20] in other ethnic populations [47, 48]. The FLI has initially been developed in a large epidemiological study from the general population and was tested against the diagnosis of a fatty liver by a single-operator ultrasonography (US) according to four stringent US-criteria [49] that in turn had shown to diagnose NAFLD defined by a histological confirmed fat content of $>30 \%$ with a sensitivity of $83 \%$ and specificity of $100 \%$ [18]. US has shown comparable rates of sensitivity in comparison to other advance imaging techniques such as $1 \mathrm{H}-\mathrm{MRS}$, although the specificity may be lower [50]. The FLI has been shown to perform equally good in men and women [47, 48], though some authors did find different cut-off points depending on sex [48].

Indirect measures of hepatic steatosis by indexes such as the FLI but also by imaging techniques fail at making the important distinction between NAFLD and NASH [20, 51]. However, due to the associated high costs, sampling error and morbidity with liver biopsies, this approach according to current consensus guidelines is only justified if clinical history, examination, laboratory results and abdominal ultrasound [52] indicate sever NAFLD or NASH. 
In addition to its application for detecting NAFLD, the index has been shown to be a useful predictor of arteriosclerosis development, independent of established classical risk factors in particular in those patients with a score $\geq 60$ [53], and may also be an independent predictor for the development of arterial fibrillation [54], diabetes [55], cardiovascular and all-cause mortality [21, 24]. If these results are directly transferable to patients with hypopituitarism with their unique hormonal setting demands however further evaluation.

A further limitation is the cross-sectional non-controlled design of our study. Reasons for not using GHD replacement therapy are various and may range from missing subjective or objective benefit from treatment as well as development of side effects or a general refusal of daily injections. Further prospective studies including a separate analysis of $\mathrm{HC}$ replacement regimes are therefore needed to evaluation the obviously complex role of GHD and HC in NAFLD among patients with pituitary dysfunction. Despite these limitations, we believe our data provide important implications for a better understanding NAFLD in general and its management of in patients with pituitary insufficiencies.

\section{Conclusion}

In summary we could show that while HC dosage affects FLI as an estimate of NAFLD in patients with pituitary adenomas the benefit of GH replacement still needs to be determined. In contrast to reports in $\mathrm{CD}$ patients with active disease, NAFLD in those biochemically controlled was not significantly increased in comparison to NFAP patients. Our study also contributes to the understanding of the role of cortisol in the development of NAFLD. Further studies should assess the diagnostic accuracy in comparison to histological criteria and its prognostic implications in this special patient population.

Acknowledgments This study was in part supported by an unrestricted research Grant from Pfizer (WI194219). The funding source played no role in the study design, analysis or interpretation of the data, writing of the manuscript or submission process. Open access funding provided by Max Planck Society.

Funding This study was in part supported by an unrestricted research Grant from Pfizer (WI194219). The funding source played no role in the study design, analysis or interpretation of the data, writing of the manuscript or submission process. Open access funding provided by Max Planck Society.

\section{Compliance with ethical standards}

Conflict of interest G.K.S. has been a consultant for Sandoz and Pfizer and has participated in medical education activities organized by, and has received investigator-initiated research grants from Pfizer. M.K.A. has received honoraria for public speaking from Pfizer and
NovoNordisk and reimbursement for travel expenses to attend conferences from Pfizer and Lilly. M.R.S. has received reimbursement for travel expenses to attend conferences from Lilly. M.K.A. and M.R.S. have received a young investigator fellowship from Pfizer.

Ethical approval All patients gave written informed consent to be part of the NeoExNET registry and the study was approved by the ethical review board of the Ludwig Maximilian University of Munich.

Open Access This article is distributed under the terms of the Creative Commons Attribution 4.0 International License (http://crea tivecommons.org/licenses/by/4.0/), which permits unrestricted use, distribution, and reproduction in any medium, provided you give appropriate credit to the original author(s) and the source, provide a link to the Creative Commons license, and indicate if changes were made.

\section{References}

1. Clark JM (2006) The epidemiology of nonalcoholic fatty liver disease in adults. J Clin Gastroenterol 40:5-10

2. Vernon G, Baranova A, Younossi Z (2011) Systematic review: the epidemiology and natural history of non-alcoholic fatty liver disease and non-alcoholic steatohepatitis in adults. Aliment Pharmacol Ther 34:274-285

3. Targher G, Arcaro G (2007) Non-alcoholic fatty liver disease and increased risk of cardiovascular disease. Atherosclerosis 191:235-240

4. Clayton R, Raskauskiene D, Reulen R, Jones P (2010) Mortality and morbidity in Cushing's disease over 50 years in Stoke-onTrent, UK: audit and meta-analysis of literature. J Clin Endocrinol Metab 96:632-642

5. Bülow B, Hagmar L, Mikoczy Z, Nordström CH, Erfurth EM (1997) Increased cerebrovascular mortality in patients with hypopituitarism. Clin Endocrinol (Oxf) 46:75-81

6. Zueger T, Kirchner P, Herren C, Fischli S, Zwahlen M, Christ E, Stettler C (2012) Glucocorticoid replacement and mortality in patients with nonfunctioning pituitary adenoma. J Clin Endocrinol Metab 97:E1938-E1942

7. Dekkers O, Biermasz N, Pereira A, Roelfsema F, Van Aken M, Voormolen J, Romijn J (2007) Mortality in patients treated for Cushing's disease is increased, compared with patients treated for nonfunctioning pituitary macroadenoma. J Clin Endocrinol Metab 92:976-981

8. Feldt-Rasmussen U, Abs R, Bengtsson B-A, Bennmarker H, Bramnert M, Hernberg-Stahl E, Monson JP, Westberg B, Wilton P, Wuster C (2002) Growth hormone deficiency and replacement in hypopituitary patients previously treated for acromegaly or Cushing's disease. Eur J Endocrinol 146:67-74

9. Johannsson G, Sunnerhagen KS, Svensson J (2004) Baseline characteristics and the effects of two years of growth hormone replacement therapy in adults with growth hormone deficiency previously treated for Cushing's disease. Clin Endocrinol (Oxf) 60:550-559

10. Wagenmakers M, Roerink S, Gil L, Plantinga T, Smit J, NeteaMaier R, Hermus A (2015) Persistent centripetal fat distribution and metabolic abnormalities in patients in long-term remission of Cushing's syndrome. Clin Endocrinol (Oxf) 82:180-187

11. Colao A, Pivonello R, Spiezia S, Faggiano A, Ferone D, Filippella M, Marzullo P, Cerbone G, Siciliani M, Lombardi G (1999) Persistence of increased cardiovascular risk in patients with Cushing's disease after five years of successful cure. J Clin Endocrinol Metab 84:2664-2672 
12. Rockall A, Sohaib S, Evans D, Kaltsas G, Isidori A, Monson J, Besser G, Grossman A, Reznek R (2003) Hepatic steatosis in Cushing's syndrome: a radiological assessment using computed tomography. Eur J Endocrinol 149:543-548

13. Gardner CJ, Irwin AJ, Daousi C, McFarlane IA, Joseph F, Bell JD, Thomas EL, Adams VL, Kemp GJ, Cuthbertson DJ (2012) Hepatic steatosis, GH deficiency and the effects of GH replacement: a Liverpool magnetic resonance spectroscopy study. Eur J Endocrinol 166:993-1002

14. Nishizawa H, Iguchi G, Murawaki A, Fukuoka H, Hayashi Y, Kaji H, Yamamoto M, Suda K, Takahashi M, Seo Y (2012) Nonalcoholic fatty liver disease in adult hypopituitary patients with GH deficiency and the impact of GH replacement therapy. Eur J Endocrinol 167:67-74

15. Ichikawa T, Nakao K, Hamasaki K, Furukawa R, Tsuruta S, Ueda Y, Taura N, Shibata H, Fujimoto M, Toriyama K (2007) Role of growth hormone, insulin-like growth factor 1 and insulin-like growth factor-binding protein 3 in development of non-alcoholic fatty liver disease. Hepatol Int 1:287-294

16. Candia R, Riquelme A, Baudrand R, Carvajal CA, Morales M, Solís N, Pizarro M, Escalona A, Carrasco G, Boza C (2012) Overexpression of $11 \beta$-hydroxysteroid dehydrogenase type 1 in visceral adipose tissue and portal hypercortisolism in non-alcoholic fatty liver disease. Liver Int 32:392-399

17. Takahashi Y (2012) Essential roles of growth hormone (GH) and insulin-like growth factor-I (IGF-I) in the liver [Review]. Endocr J 59:955-962

18. Bedogni G, Bellentani S, Miglioli L, Masutti F, Passalacqua M, Castiglione A, Tiribelli C (2006) The Fatty Liver Index: a simple and accurate predictor of hepatic steatosis in the general population. BMC gastroenterology 6:33

19. Cuthbertson DJ, Weickert MO, Lythgoe D, Sprung VS, Dobson R, Shoajee-Moradie F, Umpleby M, Pfeiffer AF, Thomas EL, Bell JD (2014) External validation of the fatty liver index and lipid accumulation product indices, using $1 \mathrm{H}$-magnetic resonance spectroscopy, to identify hepatic steatosis in healthy controls and obese, insulin-resistant individuals. Eur J Endocrinol 171:561-569

20. Otgonsuren M, Estep MJ, Hossain N, Younossi E, Frost S, Henry L, Hunt S, Fang Y, Goodman Z, Younossi ZM (2014) A single non-invasive model to diagnose non-alcoholic fatty liver disease (NAFLD) and non-alcoholic steatohepatitis (NASH). J Gastroenterol Hepatol 29:2006-2013

21. Calori G, Lattuada G, Ragogna F, Garancini MP, Crosignani P, Villa M, Bosi E, Ruotolo G, Piemonti L, Perseghin G (2011) Fatty liver index and mortality: the cremona study in the 15th year of follow-up. Hepatology 54:145-152

22. Aimaretti G, Corneli G, Razzore P, Bellone S, Baffoni C, Arvat E, Camanni F, Ghigo E (1998) Comparison between InsulinInduced Hypoglycemia and Growth Hormone (GH)-Releasing Hormone + Arginine as Provocative Tests for the Diagnosis of GH Deficiency in Adults 1. J Clin Endocrinol Metab 83:1615-1618

23. Abdu T, Elhadd T, Neary R, Clayton R (1999) Comparison of the low dose short synacthen test $(1 \mu \mathrm{g})$, the conventional dose short synacthen test $(250 \mu \mathrm{g})$, and the insulin tolerance test for assessment of the hypothalamo-pituitary-adrenal axis in patients with pituitary disease. J Clin Endocrinol Metab 84:838-843

24. Gastaldelli A, Kozakova M, Højlund K, Flyvbjerg A, Favuzzi A, Mitrakou A, Balkau B (2009) Fatty liver is associated with insulin resistance, risk of coronary heart disease, and early atherosclerosis in a large European population. Hepatology 49:1537-1544

25. Mayo-Smith W, Hayes C, Biller B, Klibanski A, Rosenthal H, Rosenthal D (1989) Body fat distribution measured with CT: correlations in healthy subjects, patients with anorexia nervosa, and patients with Cushing syndrome. Radiology 170:515-518
26. Mendoza-Figueroa T, Hernandez A, Lopez MDL, Kuri-Harcuch W (1988) Intracytoplasmic triglyceride accumulation produced by dexamethasone in adult rat hepatocytes cultivated on 3T3 cells. Toxicology 52:273-286

27. Dourakis S, Sevastianos V, Kaliopi P (2002) Acute severe steatohepatitis related to prednisolone therapy. Am J Gastroenterol 97:1074-1075

28. Targher G, Bertolini L, Rodella S, Zoppini G, Zenari L, Falezza G (2006) Associations between liver histology and cortisol secretion in subjects with nonalcoholic fatty liver disease. Clin Endocrinol (Oxf) 64:337-341

29. Vegiopoulos A, Herzig S (2007) Glucocorticoids, metabolism and metabolic diseases. Mol Cell Endocrinol 275:43-61

30. Den Boer M, Voshol P, Kuipers F, Havekes L, Romijn J (2004) Hepatic steatosis: a mediator of the metabolic syndrome. Lessons from animal models. Arterioscler Thromb Vasc Biol 24:644-649

31. Letteron P, Brahimi-Bourouina N, Robin M, Moreau A, Feldmann G, Pessayre D (1997) Glucocorticoids inhibit mitochondrial matrix acyl-CoA dehydrogenases and fatty acid beta-oxidation. Am J Physiol Gastrointest Liver Physiol 272:1141-1150

32. Lemke U, Krones-Herzig A, Diaz MB, Narvekar P, Ziegler A, Vegiopoulos A, Cato AC, Bohl S, Klingmüller U, Screaton RA (2008) The glucocorticoid receptor controls hepatic dyslipidemia through Hes1. Cell Metab 8:212-223

33. Basu R, Singh RJ, Basu A, Chittilapilly EG, Johnson MC, Toffolo G, Cobelli C, Rizza RA (2005) Obesity and type 2 diabetes do not alter splanchnic cortisol production in humans. J Clin Endocrinol Metab 90:3919-3926

34. Paterson JM, Morton NM, Fievet C, Kenyon CJ, Holmes MC, Staels B, Seckl JR, Mullins JJ (2004) Metabolic syndrome without obesity: hepatic overexpression of 11ß-hydroxysteroid dehydrogenase type 1 in transgenic mice. Proc Natl Acad Sci USA 101:7088-7093

35. Morgan SA, McCabe EL, Gathercole LL, Hassan-Smith ZK, Larner DP, Bujalska IJ, Stewart PM, Tomlinson JW, Lavery GG (2014) $11 \beta$-HSD1 is the major regulator of the tissue-specific effects of circulating glucocorticoid excess. Proc Natl Acad Sci USA 111:2482-2491

36. Wake DJ, Rask E, Livingstone DEW, Söderberg S, Olsson T, Walker BR (2003) Local and systemic impact of transcriptional upregulation of $11 \beta$-hydroxysteroid dehydrogenase type 1 in adipose tissue in human obesity. J Clin Endocrinol Metab 88:3983-3988

37. Walker BR, Connacher AA, Lindsay RM, Webb DJ, Edwards C (1995) Carbenoxolone increases hepatic insulin sensitivity in man: a novel role for 11-oxosteroid reductase in enhancing glucocorticoid receptor activation. J Clin Endocrinol Metab 80:3155-3159

38. Andrews RC, Rooyackers O, Walker BR (2003) Effects of the $11 \beta$-hydroxysteroid dehydrogenase inhibitor carbenoxolone on insulin sensitivity in men with type 2 diabetes. J Clin Endocrinol Metab 88:285-291

39. Livingstone DE, Walker BR (2003) Is 11ß-hydroxysteroid dehydrogenase type 1 a therapeutic target? Effects of carbenoxolone in lean and obese Zucker rats. J Pharmacol Exp Ther 305:167-172

40. Rosenstock J, Banarer S, Fonseca VA, Inzucchi SE, Sun W, Yao W, Hollis G, Flores R, Levy R, Williams WV (2010) The 11- $\beta$ hydroxysteroid dehydrogenase type 1 inhibitor INCB13739 improves hyperglycemia in patients with type 2 diabetes inadequately controlled by metformin monotherapy. Diabetes Care 33:1516-1522

41. Sherlock M, Reulen R, Alonso AA, Ayuk J, Clayton R, Sheppard M, Hawkins M, Bates A, Stewart P (2009) ACTH deficiency, higher doses of hydrocortisone replacement, and radiotherapy are independent predictors of mortality in patients with acromegaly. J Clin Endocrinol Metab 94:4216-4223 
42. Adams LA, Feldstein A, Lindor KD, Angulo P (2004) Nonalcoholic fatty liver disease among patients with hypothalamic and pituitary dysfunction. Hepatology 39:909-914

43. Quinkler M, Miodini Nilsen R, Zopf K, Ventz M, Øksnes M (2015) Modified-release hydrocortisone decreases BMI and $\mathrm{HbA} 1 \mathrm{c}$ in patients with primary and secondary adrenal insufficiency. Eur J Endocrinol 172:619-626

44. Johannsson G, Nilsson AG, Bergthorsdottir R, Burman P, Dahlqvist P, Ekman B, Engström BE, Olsson T, Ragnarsson O, Ryberg M, Wahlberg J, Biller BMK, Monson JP, Stewart PM, Lennernäs H, Skrtic S (2011) Improved cortisol exposure-time profile and outcome in patients with adrenal insufficiency: a prospective randomized trial of a novel hydrocortisone dual-release formulation. J Clin Endocrinol Metab 97:473-481

45. Giordano R, Guaraldi F, Marinazzo E, Fumarola F, Rampino A, Berardelli R, Karamouzis I, Lucchiari M, Manetta T, Mengozzi $G$ (2015) Improvement of anthropometric and metabolic parameters, and quality of life following treatment with dualrelease hydrocortisone in patients with Addison's disease. Endocrine 51:360-368

46. Björnsdottir S, Øksnes M, Isaksson M, Methlie P, Nilsen RM, Hustad S, Kämpe O, Hulting AL, Husebye ES, Løvås K (2015) Circadian hormone profiles and insulin sensitivity in patients with Addison's disease: a comparison of continuous subcutaneous hydrocortisone infusion with conventional glucocorticoid replacement therapy. Clin Endocrinol (Oxf) 83:28-35

47. Motamed N, Sohrabi M, Ajdarkosh H, Hemmasi G, Maadi M, Sayeedian FS, Pirzad R, Abedi K, Aghapour S, Fallahnezhad M, Zamani F (2016) Fatty liver index vs waist circumference for predicting non-alcoholic fatty liver disease. World J Gastroenterol 22:3023-3030

48. Yang B-L, Wu W-C, Fang K-C, Wang Y-C, Huo T-I, Huang Y-H, Yang H-I, Su C-W, Lin H-C, Lee F-Y (2015) External validation of fatty liver index for identifying ultrasonographic fatty liver in a large-scale cross-sectional study in Taiwan. PLoS ONE 10:e0120443

49. Sanyal AJ (2002) AGA technical review on nonalcoholic fatty liver disease. Gastroenterology 123:1705-1725

50. Bohte AE, Werven JR, Bipat S, Stoker J (2010) The diagnostic accuracy of US, CT, MRI and 1H-MRS for the evaluation of hepatic steatosis compared with liver biopsy: a meta-analysis. Eur Radiol 21:87-97

51. Mishra P, Younossi ZM (2007) Abdominal ultrasound for diagnosis of nonalcoholic fatty liver disease (NAFLD). Am J Gastroenterol 102:2716-2717

52. Chalasani N, Younossi Z, Lavine JE, Diehl AM, Brunt EM, Cusi K, Charlton M, Sanyal AJ (2012) The diagnosis and management of non-alcoholic fatty liver disease: practice Guideline by the American Association for the Study of Liver Diseases, American College of Gastroenterology, and the American Gastroenterological Association. Hepatology 55:2005-2023

53. Kozakova M, Palombo C, Paterni Eng M, Dekker J, Flyvbjerg A, Mitrakou A, Gastaldelli A, Ferrannini E (2012) Fatty liver index, gamma-glutamyltransferase, and early carotid plaques. Hepatology 55:1406-1415

54. Käräjämäki AJ, Pätsi O-P, Savolainen M, Kesäniemi YA, Huikuri H, Ukkola O (2015) Non-alcoholic fatty liver disease as a predictor of atrial fibrillation in middle-aged population (OPERA Study). PLoS ONE 10:e142937

55. Bozkurt L, Göbl CS, Tura A, Chmelik M, Prikoszovich T, Kosi L, Wagner O, Roden M, Pacini G, Gastaldelli A (2012) Fatty liver index predicts further metabolic deteriorations in women with previous gestational diabetes. PLoS ONE 7:e32710 